International Journal of Accounting Information Systems (forthcoming)

\title{
Assurance on XBRL Instance Document: A Conceptual Framework of Assertions
}

\author{
Rajendra P. Srivastava \\ Ernst \& Young Professor and Director \\ Ernst \& Young Center for Auditing Research and Advanced Technology \\ School of Business, The University of Kansas \\ 1300 Sunnyside Avenue, Lawrence, Kansas 66045 \\ Email: rsrivastava@ku.edu \\ and \\ Alexander Kogan \\ Professor of Accounting Information Systems \\ Department of Accounting, Business Ethics, and Information Systems \\ Rutgers Business School - Newark and New Brunswick \\ Rutgers University \\ 1 Washington Park, Newark, NJ 07102 \\ Email: kogan@rutgers.edu
}

November 23, 2009 


\title{
Assurance on XBRL Instance Document: A Conceptual Framework of Assertions
}

\begin{abstract}
XBRL stands for extensible business reporting language. It is an XML based computer language for reporting business information. In December 2008, the United States Securities and Exchange Commission (US SEC) voted to require public filers to provide a supplemental exhibit of their financial statements (including footnotes) in XBRL, with the top approximately 500 public companies required to comply with this new requirement starting on June 15, 2009, and the phase-in of this requirement for the other filers to be completed on June 15, 2011. The file created using the XRBL language is called an XBRL instance document. Under this requirement, the filers are not required to obtain a third party assurance on the XBRL instance document. The main reason for not requiring a third party independent assurance of XBRL instance documents is to encourage filers to comply with the SEC requirement without incurring much added costs. In addition, to encourage the filers to comply with this requirement, the SEC is not holding filers legally liable of any errors in the filed XBRL instance documents so long as they look similar to the standard reports when viewed using the SEC viewer.

Even though the SEC is not currently requiring a third party assurance of the XBRL instance documents of the SEC filings, it is in the best interest of the public that these documents be assured. Although there have been efforts by both the practitioners and academics to investigate issues involved in providing assurance on XBRL documents, these efforts have been focused on the specifics of the assurance process and the difficulties involved in it, and not on developing a framework of assertions. Even the American Institute of Certified Public Accountants recent publication SOP 09-1 provides only an illustrative list of management assertions for handling the XBRL-tagging engagements under the SSAEs as agreed-upon procedures without considering a framework. Without a conceptual framework, the assurance process for XBRL instance document would be ad hoc and inconsistent. This paper develops a set of assertions for providing assurance on XBRL instance documents similar to the management assertions for financial audits. Further, we discuss how such a framework would assist auditors in planning and evaluating such an engagement by collecting appropriate items of evidence pertaining to specific assertions to form an opinion whether the instance document is a true representation of the standard format (i.e., ASCII or HTML) document. We also discuss how the use of new technology would make the assurance process more effective and efficient.
\end{abstract}

Key words: Assurance, Assertions, XBRL, Instance Document, Framework 


\section{Assurance on XBRL Instance Document: A Conceptual Framework of Assertions}

\section{INTRODUCTION}

The main purpose of this paper is to develop a conceptual framework of assertions for providing assurance on XBRL instance documents created under the SEC interactive data filing requirements (SEC 2009). Similar to financial audits, we develop a comprehensive set of assertions that are essential for providing quality assurance on XBRL instance documents. In addition to developing the basic assertions for a quality assurance, we demonstrate, through examples, the assertion based approach to be the most effective and efficient way to provide assurance services on XBRL instance documents.

In December 2008, the United States Securities and Exchange Commission (US SEC) voted to require public filers to provide a supplemental exhibit of their financial statements (including footnotes) in XBRL, with the top approximately 500 public companies required to comply with this new requirement starting on June 15, 2009, and the phase-in of this requirement for the other filers to be completed on June 15, 2011 (SEC 2009). The SEC final rules state that “interactive data must meet investor expectations of reliability and accuracy” (SEC 2009, p. 6793). However, the final rules impose no independent assurance requirements on the provided interactive data, and instead express confidence that "market forces will encourage companies to provide interactive data that accurately reflects the corresponding traditional format data in the traditional format filing” (SEC 2009, p. 6793). Moreover, the final rules do not define precisely what “accurately reflects” means. 
Public Company Accounting Oversight Board (PCAOB 2005) through its Staff Questions and Answers provides general guidance as to the nature of assurance without giving any specifics of the attributes or assertions to be tested and validated for the assurance services on XBRL instance documents. Similar to PCAOB, Assurance Working Group (AWG) of XBRL International (2006, see also, e.g., Boritz and No 2008) provides similar guidance but does not provide any framework of assertions for the assurance process.

Recently, the American Institute of Certified Public Accountants published the Statement of Position 09-1: Performing Agreed-Upon Procedures Engagements That Address the Completeness, Accuracy, or Consistency of XBRL-Tagged Data (AICPA 2009). According to the XBRL Assurance Task Force of the AICPA Assurance Services Executive Committee, the SOP 09-1 is an interpretive publication and recommendation regarding application of Statement on Standards for Attestation Engagements (SSAEs) for engagements in which a practitioner performs and reports on agreed-upon procedures related to the completeness, accuracy, or consistency of XBRL-tagged data. Through the SOP 09-1, the AICPA asserts that:

"In order for XBRL to be a useful tool for investors and other users of business information, the data contained in XBRL files must be accurate and reliable. Preparers of XBRL-tagged data may be issuers or nonissuers and are responsible for providing accurate information in their XBRL files on which investors and other users of business information may rely" (item 4, p. 2).

The AICPA further contends that:

"Because of factors such as a company's limited experience with XBRL and its desire to ensure the accuracy and reliability of the data, management may express interest in engaging a practitioner to assist them in assessing the completeness, accuracy, or consistency of the XBRL-tagged data” (item 6, p. 2).

Since the SOP 09-1 is only providing guidance to practitioners as to how they can handle the XBRL-tagging engagements under the SSAEs as agreed-upon procedures, SOP 09-1 does 
not provide a comprehensive list of management assertions that need to be tested for the completeness, accuracy, or consistency of the XBRL-tagged data under the SEC requirements (SEC 2009). However, it provides, as an illustration, a list of management assertions and the corresponding procedures and potential findings. These management assertions seem to be developed in an ad hoc way without a framework and thus may be incomplete. For example, as discussed in Section 2, the XBRL-tagged data would be inaccurate if it violated the general XML syntax rules (Our assertion 2.1 Well-Formedness). In the present paper, we use the risk based approach to argue for a comprehensive list of management assertions for preparing and providing assurance on the XBRL-tagged document.

Although PricewaterhouseCoopers (Boritz and No 2008, see also Boritz and No 2003) had performed an assurance service on the United Technologies Corporation's (UTC) instance document without a formal set of assertions, in an attempt to indentify issues and difficulties involved in the assurance process, Boritz and No (2008) performed a mock audit of the $10 \mathrm{Q}$ XBRL instance document of UTC. Their approach consisted primarily of tracing every item in the paper version to the XBRL instance document and every item from the XBRL document to the paper version. It took them about 63 hours to complete the task. At the end of the process, their conclusion was that they had high assurance that "the 10-Q XBRL-Related Documents were a complete and accurate reflection of UTC's 10-Q.” Although based on the detailed work done by Boritz and No (2008), one can say that their audit approach was of high quality, however, there is no reference point or framework to judge whether they did everything that was needed to be done to make sure that the instance document truly represented the paper document. The question again is what constitutes “true representation”. 
In a recent paper, Plumlee and Plumlee (2008) discuss the issues involved in providing assurance on XBRL instance documents. They talk about materiality issues, statistical sampling issues, and control related issues. However, they do not talk about or discuss a conceptual framework of assertions for the assurance process as one would need to conduct the service.

The general requirements under the SEC final rules (Section 405 of Regulation S-T, SEC 2009) concerning the content of the XBRL tagged exhibit are:

"An Interactive Data File must consist of only a complete set of information for all periods required to be presented in the corresponding data in the Related Official Filing, no more and no less ...” (SEC 2009, p. 6815)

As far as the format of the XBRL tagged exhibit is concerned, the rules impose compliance with the following requirements:

“(1) Data elements and labels.

(i) Element accuracy. Each data element (i.e., all text, line item names, monetary values, percentages, numbers, dates and other labels) contained in the Interactive Data File reflects the same information in the corresponding data in the Related Official Filing;

(ii) Element specificity. No data element contained in the corresponding data in the Related Official Filing is changed, deleted, or summarized in the Interactive Data File;

(iii) Standard and special labels and elements. Each data element contained in the Interactive Data File is matched with an appropriate tag from the most recent version of the standard list of tags specified by the EDGAR Filer Manual. A tag is appropriate only when its standard definition, standard label and other attributes as and to the extent identified in the list of tags match the information to be tagged, except that:

(A) Labels. An electronic filer must create and use a new special label to modify a tag's existing standard label when that tag is an appropriate tag in all other respects (i.e., in order to use a tag from the standard list of tags only its label needs to be changed); and

(B) Elements. An electronic filer must create and use a new special element if and only if an appropriate tag does not exist in the standard list of tags for reasons other than or in addition to an inappropriate standard label; and

(2) Additional mark-up related content. The Interactive Data File contains any additional mark-up related content (e.g., the eXtensible Business Reporting Language tags themselves, identification of the core XML documents used and other technology related 
content) not found in the corresponding data in the Related Official Filing that is necessary to comply with the EDGAR Filer Manual requirements.” (SEC 2009, p. 6815)

To assure the accuracy of the interactive data exhibit, the final rules state that the SEC will do the following:

“... we plan to use validation software to check interactive data for compliance with many of the applicable technical requirements and to help the Commission identify data that may be problematic. For example, we expect the Commission's technology to:

- Check if required conventions (such as the use of angle brackets to separate data) are applied properly for standard and, in particular, non-standard special labels and tags;

- Identify, count, and provide the staff with easy access to non-standard special labels and tags;

- Identify the use of practices, including some the XBRL U.S. Preparers Guide contains, that enhance usability;

- Facilitate comparison of interactive data with disclosure in the corresponding traditional format filing;

- Check for mathematical errors; and

- Analyze the way that companies explain how particular financial facts relate to one another.” (SEC 2009, p. 6793).

"The Commission will seek to ensure that linkbases not only comply with technical requirements but also are not used to evade accounting standards.” (SEC 2009, p. 6793, footnote 229)

After a closer look at the SEC final rules and its position on the accuracy and completeness of XBRL tagged documents, and also at the other efforts on either providing assurance (PWC, and Boritz and No 2008) on XBRL instance documents or the guidance provided by AICPA (2008) and PCAOB (2005), we come to a conclusion that there seems to be a general lack of conceptual framework of assertions that would make the assurance process effective and efficient. These current approaches seem to be similar to what the audit process used to be some 60 years ago before the publication of “Philosophy of Auditing” by Mautz and Sharaf (1963); a bunch of procedures to be performed specific to each balance sheet account. In 
the present paper, we logically argue for a set of assertions that determine the quality of the XBRL document created from the traditional financial statements that have been audited in accordance with the current requirements and filed with the SEC. These assertions then lead to identifying appropriate audit evidence for providing assurance on these documents.

While the SEC (2009) mandated companies to add an exhibit of their financial statements in XBRL tagged format, "Rule 406T ... deems interactive data files not filed for purposes of various provisions under the federal securities laws” (SEC 2009, p. 6794). Additionally, the rules state that:

"There is no additional basis for auditor liability based on data tagging. Also, an auditor will not be required to apply AU Sections 550, 711 or 722 to interactive data provided in an exhibit or to the related viewable interactive data. In this regard, we also note that we are not requiring that filers involve third parties, such as auditors or consultants, in the creation of their interactive data filings. " (SEC 2009, p. 6796)

In addition, the SEC asserts:

"We are adopting amendments that exclude interactive data from the officer certification requirements of Rules $13 \mathrm{a}-14$ and $15 \mathrm{~d}-14$. We believe that adopting these amendments is part of striking an appropriate balance between avoiding unnecessary cost and expense and encouraging accuracy in regard to interactive data." (SEC 2009, p. 6797).

While waiving the assurance requirements and providing liability protection for XBRL filings is a very significant relief to the SEC filers, and will moderate their resistance to this new filing requirement, this is a short-time band-aid that has to be eliminated sooner rather than later, as more and more financial statement users will start tying their systems to the "interactive data" in XBRL provided online by the SEC. Since "interactive data" is designed to be automatically utilized by computers without human intervention and for various purposes, it will completely replace the standard format data in most applications, and thus, has to be assured to be relied on. The development of a conceptual framework for this assurance is the topic of this paper. We 
limit our attention to the current mode of providing an XBRL version of financial statements in addition to the traditional format. Therefore, we assume that the traditional format statements have been audited in accordance with the current requirements, and can be relied on as a benchmark for comparison. When the traditional format financial statements are phased out, and the XBRL version becomes the main (and only) format of the SEC filings, this framework will have to be revisited to be merged into the statutory audit methodology.

We assume that the reader is familiar with the fundamental concepts of XBRL (including taxonomy extensions) to the extent that they are described in XBRLUS (2008b). The paper is divided into five sections. Section 2 develops the main assertions for XBRL assurance services. Section 3 describes relevant technology that would be important for providing assurance on XBRL instance documents. Section 4 describes other related issues pertinent to XBRL instance documents. Finally Section 5 provides a summary and conclusion of the study.

\section{ASSERTIONS FOR XBRL ASSURANCE}

In this section we propose a set of assertions that can serve as the criteria to provide assurance on the XBRL instance document created under the SEC interactive data filing requirements (SEC 2009). Violation of these assertions will constitute errors in the XBRL instance documents. These assertions are conceptualized based on the set of assertions proposed by AICPA (2006a) and the set of assertions for information quality proposed by Bovee, Srivastava and Mack (2003). To derive the appropriate assertions, we follow the methodology of information assurance (Lamm and Haimes, 2002) as well as the general audit standards guidance (in particular, SAS 107 / AU 312 “Audit Risk and Materiality in Conducting an Audit,” AICPA 2006b), and start by analyzing the risk scenarios on the basis of enumerating adverse events that 
can result in material deficiencies of the XBRL formatted statements given that the traditional financial statements being filed with the SEC are audited.

As stated earlier, the main assertion is "The XBRL instance document is a true representation of the electronic document (ASCII or HTML) filed with the SEC”. One can find more specific guidance in the Q\&A provided by the PCAOB Staff (PCAOB, 2005) and in the white paper by the Assurance Working Group (AWG) of XBRL International (2006).

The structure of XBRL instance documents makes it natural to decompose the risk of deficiencies analysis into the data deficiency and meta-data deficiency parts. The former refers to the possible deficiencies of the facts that are marked up in the XBRL instance document, while the latter refers to the possible deficiencies of the mark-up itself, including both the deficiencies of the mark-up in the instance document and deficiencies of the XBRL taxonomies. While this decomposition is useful for structuring the assertions that assurance attests to, the two parts are closely interlinked and will often be tested together. The risks of deficiencies identified below incorporate and systematize all the problems covered by management review objectives described in XBRLUS (2008b, section 8).

Possible data deficiencies in the XBRL instance document ${ }^{1}$ include:

- Failure to include in the instance document all relevant business facts from the traditional format document filed with the SEC. In the case of a $10 \mathrm{~K}$ filing the omission may pertain to a line item on the financial statements, or a footnote. An example of such an omission in a $10 \mathrm{~K}$ filing would be if the audited financial statement provides the amount of accounts receivable for the current quarter but the XBRL instance document omits this datum. This will constitute a material deficiency making the XBRL instance document of $10 \mathrm{~K}$ inconsistent with the

\footnotetext{
${ }^{1}$ The term "document” is used in this article for any document that is filed with the SEC under the Interactive Data to Improve Financial Reporting; Final Rule (SEC 2009). For example, document could mean 10Q, 10K, 8K, or any other document filed with the SEC in the XBRL format. A business fact to be tagged may be present in any of the documents filed with the SEC. For example, it may be contained in the financial statements of 10K or 10Q, or in the footnotes of $10 \mathrm{~K}$, and $10 \mathrm{Q}$.
} 
traditional format filing. The audit assertion aimed at this risk will be called Completeness.

- Insertions of a business fact or facts not present in the traditional format document. For a $10 \mathrm{~K}$ document, an example of such an insertion would be if the XBRL instance document of the $10 \mathrm{~K}$ contains an element describing the amount of accounts receivable for the current quarter, while the audited financial statement does not provide it. This will constitute a material deficiency making the XBRL instance document inconsistent with the traditional format filing. The audit assertion aimed at this risk will be called Existence.

- Erroneous element values associated with the business fact being tagged in the traditional format document and/or attribute values associated with the business fact being tagged. An example of an erroneous element value, in the case of a $10 \mathrm{~K}$ document, would be the XBRL instance document describing the amount of accounts receivable for the current quarter as $\$ 90,000.00$ while the audited financial statement showing this amount to be $\$ 100,000.00$. An example of an erroneous attribute value, in the case of a $10 \mathrm{~K}$ filing, would be a wrong contextRef value that misidentifies $\$ 90,000.00$ as the amount of accounts receivable for the current quarter, while the traditional format document states that it is actually for the previous quarter. The audit assertion aimed at this risk will be called Accuracy. This assertion would have two components; one would deal with the accuracy of the value of the element (Element Accuracy) and the other would deal with the accuracy of the attributes' values (Attribute Accuracy).

Possible deficiencies of the mark-up in the XBRL instance document include:

- Erroneous tagging of a business fact that violates XML syntax rules. For example, in the case of a $10 \mathrm{~K}$ filing, a missing closing tag such as </AccounsReceivable> would make the XBRL instance document of a 10K filing severely deficient and likely make it unusable for computer applications. The audit assertion aimed at this risk will be called Well-formedness.

- Erroneous tagging of a business fact that violates XML Schema. This includes non-compliance with either the standard XBRL taxonomies or taxonomy extensions used by the filer. An example of such deficiency for a $10 \mathrm{~K}$ document would be an element with a missing required attribute such as unitRef. Such document would cause processing problems for XBRL software because of lack of crucial substantive information. The audit assertion aimed at this risk will be called Validity.

- Inappropriate choice of an XBRL element to tag a business fact present in the traditional format document. For example, for a $10 \mathrm{~K}$ filing, if the audited financial statement provides the amount of accounts receivable for the current quarter but the XBRL instance document tags this datum using the element $<$ CurrentAssets $>$, this will constitute a material deficiency making the XBRL 
instance document inconsistent with the traditional format filing. The audit assertion aimed at this risk will be called Proper Representation.

Possible deficiencies in meta-data external to XBRL instance document:

- Improper choice of general and industry-specific XBRL taxonomies by the filer. An example of such deficiency, in the case of a 10K filing, will happen if an insurance company does not utilize the approved US GAAP - Insurance XBRL taxonomy and relies instead only on the US GAAP - Commercial and Industrial XBRL taxonomy. The audit assertion aimed at this risk will be called Proper Taxonomies.

- Violations of XML or XBRL language rules in XBRL taxonomy extensions by the filer. An example of such deficiency will happen if a taxonomy extension includes a definition of new element which does not have the required xbrli:periodType attribute. The audit assertion aimed at this risk will be called Valid Taxonomy Extensions.

- Inappropriate introduction of new elements in XBRL taxonomy extensions. This type of deficiency can range from introducing unnecessary new elements to replacing ones in standard taxonomies to improper attribute values. For example, in the case of a $10 \mathrm{~K}$ filing, an insurance company may decide to introduce an extension element called $<$ InsuranceReceivable $>$ which is functionally equivalent to the standard element $<$ PremiumsReceivable $>$ in the US GAAP - Insurance XBRL taxonomy. Another example of such deficiency would be an airline company introducing a new element <FlightEquipment> with the balance attribute value set to "credit". The audit assertion aimed at this risk will be called Proper Extension Elements.

- Inappropriate / erroneous linkbases in XBRL taxonomy extensions (including the choice of inappropriate/misleading labels). An example of such a deficiency related to a $10 \mathrm{~K}$ filing (in the Calculation Linkbase) would be an airline company that introduced a new element $<$ FlightEquipment $>$ and created an erroneous $<$ calculationArc $>$ going from $<$ CurrentAssets $>$ to $<$ FlightEquipment $>$ (instead of the correct one going from <PropertyPlantAndEquipment $>$ to $<$ FlightEquipment $>$. The audit assertion aimed at this risk will be called Proper Linkbases.

The content of an audit assertion is the claim that a specified set of deficiencies affecting the audit subject matter is not present. Therefore, XBRL assurance process should be driven by assertions stating that the possible deficiencies identified above are not present in the XBRL report under examination. If the above list of deficiencies is sufficiently comprehensive, then 
satisfying the set of assertions based on them will thus assure that the audited instance document faithfully represents the filed document.

Based on the risks of deficiencies identified above, we present below a set of assertions that we propose for assuring that the XBRL instance document "is a true representation of the electronic document (ASCII or HTML) filed with the SEC”. Figure 1 provides a schematic representation of the proposed assertions and sub-assertions. The main assertion is true if the following assertions are true:

\section{Assertions about business facts in XBRL instance document}

Completeness:All relevant business facts including footnotes and other non-financial information that are required to be reported in the traditional format document are tagged in the XBRL instance document.

Existence: There is no tagged business fact in the XBRL instance document that is not present in the traditional format document.

Accuracy: The values of all business concepts tagged in the XBRL instance document and / or the corresponding attribute values (such as context, unit, etc.) accurately represent the facts in the traditional format document. Thus, this assertion has two sub-assertions: Element Accuracy, and Attribute Accuracy.

\section{Assertions about meta-data in XBRL instance document}

Well-formedness: The XBRL instance document is well-formed, i.e., it complies with all XML syntax rules.

Validity: The XBRL instance document is valid, i.e., it complies with all rules of XBRL and referenced XBRL taxonomies. 
Proper Representation: The tagged business fact in the XBRL instance document properly represents the facts in the traditional format document

\section{Assertions about meta-data external to XBRL instance document}

Proper Taxonomies: The business facts tagged in the XBRL instance document uses appropriate general and industry-specific XBRL taxonomies.

Valid Taxonomy Extensions: The XBRL taxonomy extensions referenced by the XBRL instance document are valid, i.e., they comply with all rules of XML and XBRL.

Proper Extension Elements: The new elements in the XBRL taxonomy extensions referenced by the XBRL instance document are introduced appropriately, i.e., the extension tag along with its appropriate attributes is created only when there is no standard tag available.

Proper Linkbases: The linkbases in the XBRL taxonomy extensions referenced by the XBRL instance document are appropriate.

The "proper linkbases" assertion includes the respective sub-assertions for each type of linkbases in the XBRL taxonomies. In particular, the verification of the "proper label linkbase" assertion will require ascertaining that the labels assigned to new elements or re-assigned to the standard elements in the extension taxonomies are chosen appropriately. The verification of the "proper presentation linkbase” assertion will require ascertaining that the hierarchical structure described by the introduced arcs is appropriate for the filer. Similarly, the verification of the "proper calculation linkbase" assertion will require ascertaining that the aggregation rules described by the arcs are appropriate for the elements. The verification of the "proper definition linkbase" assertion will require ascertaining that the introduced dimension relationships are 
appropriate. Finally, the verification of the "proper reference linkbase" assertion will require ascertaining that the arcs refer to appropriate external regulations or standards.

While some of the assertions above ("well-formedness", "validity” and "valid taxonomy extensions”) can be easily verified automatically using XBRL processing software, some other assertions (“completeness”, “existence”, “accuracy”, and "proper taxonomies”) require human analysis of intermediate level of expertise, and the rest of the assertions ("proper representation", “proper extension elements”, and "proper linkbases”) require high-level human judgment of high level of expertise.

The auditing (as well as preparation) of XBRL instance documents will be greatly simplified and standardized if XBRL US succeeds in their quest to create and maintain an XBRL taxonomies validation system acting as "an interoperable component that will serve as a common core to enable the editing, distribution and processing of validation criteria or consistency checks” as described in XBRLUS (2008a). Another extremely important tool facilitating audit procedures to support the assertions described above would be XBRL processing software which is enabled to maintain and visualize a manually established mapping between the facts in the traditional format document and elements in the XBRL instance document.

\section{XBRL INSTANCE DOCUMENT ASSURANCE PROCESS}

In this section we discuss the assertion based approach to providing assurance on XBRL instance document. In addition, we compare and contrast the proposed assertions in this paper with the assertions published by the AICPA in SOP 09-1 (AICPA 2009). To ascertain that the main assertion "XBRL instance document is a true representation of the electronic document (ASCII or HTML) filed with the SEC (see Figure 1)" is true, the assurance provider collects evidence to determine whether all the relevant assertions listed in the previous section are true. 
Thus, in principle, the assurance process is similar to the traditional audit of collecting, evaluating and aggregating evidence to ascertain that each assertion is true at a high level of confidence. We list procedures in Tables 1-3 that can be performed by an expert auditor along with the possible use of intelligent software to conduct the assurance service on the XBRL instance document. The intelligent financial statements parsing technology developed for the FRAANK project (Bovee et al 2005, Nelson et al. 2000) can be potentially adapted in the future to implement the intelligent software functions described in Tables 1-3. The purpose of these tables is not to provide a comprehensive set of detailed procedures, but rather to describe such possible procedures at the conceptual level. Some of our suggested assertions are similar to AICPA's assertion. For these assertions, one can refer to the detailed list of procedures provided by SOP 09-1.

The first column in Tables 1-3 lists our suggested assertions. The second column lists the assertions provided by the AICPA. As one can see from Table 2, one can see that AICPA's assertions list does not contain our assertions 2.1 Well-Formedness pertaining to the meta-data in the XBRL instance document. Also, as seen from Table 3, our assertion 3.4 Proper Linkbases pertaining to the meta-data external to XBRL instance document relates to three assertions: 6 . Label and Label Linkbase, 7. Calculation and Calculation Linkbase, and 8. Presentation and Presentation Linkbase. In fact, our assertion 3.4 Proper Linkbases includes all the appropriate linkbases. For example, in addition to Label Linkbase, Calculation Linkbase, and Presentation Linkbase, one has to verify that Reference Linkbase and Definition Linkbase are appropriately presented.

There are two reasons for this incomplete listing of assertions in SOP 09-1. First, the objective of the AICPA was to just provide an illustrative list of assertions for the auditor to 
consider when they accept an assurance engagement on XBRL instance document as an agreedupon procedures engagement. Second, the AICPA's list may have been created on an ad hoc basis without a framework. Our approach of using a framework to develop a list of assertions is a structured approach and it enriches the thought process.

\section{OTHER ISSUES IN ASSURING XBRL INSTANCE DOCUMENTS}

In this section we discuss issues that relate to XBRL instance documents of the financial statements filed with the SEC. Plumlee and Plumlee (2008) have raised these issues. We further elaborate on these issues but provide no resolutions to these issues as they are beyond the scope of this paper.

\subsection{Materiality}

Usually, the materiality concept used in the audited financial statements filed with the SEC is at the overall level. However, when the same information is presented in the XBRL format where users of the information can pick any line item from the tagged financial statement for decision purposes, they may erroneously assume that each line item is accurate in itself which is not the case. Thus, their use of the individual piece of information in their decision would not accurately represent the reality. This is a major problem with the financial statements filed with the SEC under XBRL format. What will be appropriate for the decision makers when they use each line item to make their decision is the assurance at each data level, as pointed out by AWG (2006, paragraph 028). Thus, we have two kinds of materiality:

- Materiality for the entire financial statement;

- Materiality for each line item in the instance document. 
The above issue is not only relevant for the XBRL instance document but also for any electronic document that provides business information or facts. As mentioned earlier, our purpose here is just to highlight this issue rather than provide a solution.

\subsection{Inherent Risk, Control Risk, Detection Risk, and Statistical Techniques}

The American Institute of Certified Public Accountants (AICPA) uses the audit risk model (AICPA 2006b, 2006c) for the traditional financial statement audit. Plumlee and Plumlee (2008, p. 363) raise questions about the components of the audit risk model (inherent risk, IR; control risk, CR; analytical procedures risk, APR; and detection risk, TD) as to how would they apply to the audit of the XBRL instance document? They do not provide any solution. Here we elaborate on these issues and raise further questions, especially relevance of control risk and statistical sampling.

Since major portion of the XBRL instance document is being prepared by software with human interventions possibly to add extensions and create linkbases, the reliability of such software would be of utmost importance for the reliability of the XBRL instance documents. In fact, creation of extensions and the corresponding linkbases could be automated too (e.g., the latest version of FRAANK has these built-in features, Bovee et al 2005). The risk that the software would have introduced errors would be equivalent to RMM (the risk of material misstatement represented as the product of inherent risk and control risk: $\mathrm{RMM}=\mathrm{IR} * \mathrm{CR}$, see AICPA 2006b, 2006c). The traditional definition of inherent risk (IR) and control risk (CR) would not make sense in the current situation because the nature of errors are very different as discussed in the previous section. However, it is important to assess the reliability of the software in order to determine the extent of audit; the more reliable the software the more reliable the XBRL instance document and thus the less the amount of work to be done by the auditor. The 
question then arises, how do we assess the reliability of the software? Should it be done through a test sample of SEC filing with seeded errors to create an XBRL instance document from this test sample filing and assess the reliability of the software?

In the traditional audit of financial statements, if the auditor assesses a low level of risk of material misstatement (RMM) then he/she would perform less extensive substantive tests, e.g., by selecting a smaller sample for a statistical test. Plumlee and Plumlee (2008) argue that before auditors start using statistical techniques to audit XBRL instance documents, the meanings of tolerable error and tolerable deviation need to be clarified. However, we question the use of statistical techniques in the audit of XBRL instance documents. For statistical techniques to work we need a large population of items that have identical characteristics such as inventory balance consisting of a large number of individual inventory items or accounts receivable balance consisting of a large number of customer accounts receivable balances. For instance, one can use the Mean-Per-Unit statistical technique to determine the inventory value of the population by determining the sample mean (Guy and Carmichael 1986).

However, it would not make sense to use statistical techniques to check whether business facts on the traditional format documents are properly tagged because of the following reasons. First, each business fact to be tagged on the traditional document is a unique item having very different characteristics from another business fact. Second, even if there are few business facts that may have the same characteristics, they are so small in number that statistical inference techniques will not be applicable. For example, the tag for accounts receivable, “AccountsReceivable" has "debit" as an attribute and "TotalCurrentAssests" as the parent tag while the tag for accounts payable, "AccountsPayable" has "credit" as an attribute and “TotalCurrentLiability” as the parent tag. Even if one considers all the children of one parent, 
the number may still be less than ten. Thus, the use of statistical techniques with a population size of ten would not make sense.

\section{CONCLUSION}

Starting June 15, 2009, the United States Securities and Exchange Commission (US SEC) is requiring about top 500 public companies to add to their filings with the SEC an exhibit of their financial statements in the XBRL format. Under this requirement, the filers are not required to obtain a third party assurance on the XBRL instance document. The main reason for not requiring a third party independent assurance of XBRL instance documents is to encourage filers to comply with the SEC requirement without incurring much added costs. In addition, to encourage the filers to comply with this requirement, the SEC is not holding filers legally liable of any errors in the filed XBRL instance documents so long as they look similar to the standard reports when viewed using the SEC viewer. Even though the SEC is not currently requiring a third party assurance of the XBRL instance documents of the SEC filings, it is in the best interest of the public that these documents be assured.

This paper has developed a set of assertions for providing assurance on XBRL instance documents similar to the management assertions for financial audits. Further, we have discussed how such a framework would assist auditors in planning and evaluating an assurance engagement for XBRL instance document by collecting appropriate items of evidence pertaining to specific assertions to form an opinion whether the instance document is a true representation of the text document.

In conclusion, we would like to note that the use of XBRL potentially enables reporting enhancements above and beyond what is currently available in the standard format documents. In particular, the facility of reference linkbase of XBRL makes it possible to seamlessly incorporate 
links to authoritative accounting standards documents relevant to the tagged financial facts. These references can point, in particular, to the relevant parts of the recently completed codification of the US accounting standards by FASB. The resulting XBRL version of financial statements will provide much more specific information than the conventional one about the way the accounting numbers were calculated, helping various decision makers to understand the accounting numbers better. However, such enhancement would elevate the status of the XBRL document beyond the simple add-on, and will require assurance going beyond the simple comparison with the traditional format filings as covered by the this paper. 


\section{REFERENCES}

American Institute of Certified Public Accountants (AICPA). 2009. Statement of Position 09-1: Performing Agreed-Upon Procedures Engagements That Address the Completeness, Accuracy, or Consistency of XBRL-Tagged Data. New York.

American Institute of Certified Public Accountants Assurance Services Executive Committee. 2008. The Shifting Paradigm in Business Reporting and Assurance. New York

American Institute of Certified Public Accountants (AICPA). 2006a. Statement on Auditing Standards No. 106: Audit Evidence. New York.

American Institute of Certified Public Accountants (AICPA). 2006b. Statement on Auditing Standards No. 107: Audit Risk and Materiality in Conducting an Audit. New York.

American Institute of Certified Public Accountants (AICPA). 2006c. Statement on Auditing Standards No. 111: Amendment to Statement on Auditing Standards No. 39, Audit Sampling. New York.

Assurance Working Group (AWG) of XBRL International. 2006. Interactive Data: The Impact on Assurance. New Challenges for the Audit Profession. http://www.xbrl.org/Announcements/Interactive-Data-Assurance-2006-11-10.pdf

Boritz, J. E. and W. G. No. 2008. Auditing an XBRL Instance Document: The Case of United Technologies Corporation. Working paper, University of Waterloo.

Boritz, J.E. and W. G. No. 2003. Assurance Reporting for XBRL: XARL (eXtensible Assurance Reporting Language). Reporting Trust and Data Assurances in Capital Markets: The Role of Technology Solutions, PriceWaterHouseCoopers Research Monograph: 7-16.

Bovee, M., A. Kogan, R. P. Srivastava, M. A. Vasarhelyi, K. M. Nelson, 2005. Financial Reporting and Auditing Agent with Net Knowledge (FRAANK) and eXtensible Business Reporting Language (XBRL). Journal of Information Systems, Vol. 19, No. 1 (Spring): pp. 19-41.

Bovee, M, R. P. Srivastava, and B. Mak. 2003. A Conceptual Framework and Belief-Function Approach to Assessing Overall Information Quality. International Journal of Intelligent Systems, Volume 18, No. 1, January: 51-74.

Guy, D., and D. R. Carmichael. 1986. Audit Sampling: An Introduction to Statistical Sampling in Auditing. New York, NY: Wiley.

Lamm, G.A. and Y.Y. Haimes. 2002. Assessing and managing risks to information assurance: A methodological approach. Systems Engineering, Volume 5, No. 4, 286 - 314.

Mautz and Sharaf. 1963. The Philosophy of Auditing. American Accounting Association, Sarasota, FL. 
Nelson, K. M., A. Kogan, R.P. Srivastava, M.A. Vasarhelyi, and H. Lu. 2000. Virtual auditing agents: the EDGAR Agent challenge. Decision Support Systems 28 (3): 241-253.

Plumlee, D. and M. Plumlee. 2008. Assurance on XBRL for Financial Reporting. Accounting Horizons, Vol. 22, No. 3: 353-368.

Public Company Accounting Oversight Board. 2005. Staff Questions and Answers, Attest Engagements Regarding XBRL Financial Information Furnished Under the XBRL Voluntary Financial Reporting Program on the Edgar System. Washington, DC.

Securities and Exchange Commission (SEC). 2009. Interactive Data to Improve Financial Reporting; Final Rule. Federal Register, Vol. 74, No. 26, Tuesday, February 10, 2009, Rules and Regulations: 6776-6821.

XBRL US (XBRLUS). 2008a. XBRL US Consistency Checks. Request for Proposal. http://www.xbrl.us/Documents/RFP-InstanceValidation.pdf

XBRL US (XBRLUS). 2008b. XBRL US GAAP Taxonomy Preparers Guide. http://www.xbrl.us/preparersguide/Pages/default.aspx 
Table 1: Proposed Assertions about business facts in XBRL instance document along with AICPA SOP 09-1 Assertions (AICPA 2009, Appendix C) and Suggested Assurance Procedures.

\begin{tabular}{|c|c|c|c|}
\hline \multicolumn{2}{|c|}{ Proposed Specific Assertions } & $\begin{array}{c}\text { (Approximately or partially) } \\
\text { Equivalent SOP 09-1 Assertions }\end{array}$ & Procedures as items of evidence pertaining to the assertion \\
\hline \multicolumn{2}{|c|}{$\begin{array}{l}\text { 1.1 Completeness: All relevant business facts } \\
\text { including footnotes and other non-financial } \\
\text { information that are reported on the traditional } \\
\text { format document and are required to be tagged } \\
\text { are tagged in the XBRL instance document }\end{array}$} & $\begin{array}{l}\text { 4. Completeness of XBRL-tagged Data: } \\
\text { All of the data in the source document that } \\
\text { is required to be tagged has been tagged } \\
\text { and included in the XBRL instance } \\
\text { document. } \\
\text { 5. Granularity of Tagging of Notes } \\
\text { Disclosures: Note disclosures are tagged } \\
\text { at the level required or allowed by: } \\
\text { [described (for example, SEC rules)] }\end{array}$ & $\begin{array}{l}\text { Manual (M): Trace from the source document all items that are required } \\
\text { to be tagged to the XBRL instance document and note that all these } \\
\text { business facts are tagged. } \\
\text { Intelligent Software (IS): Intelligent software can be programmed to tag } \\
\text { all the business facts. Compare programmatically each tagged fact } \\
\text { prepared for the SEC filing with the tagged facts by the intelligent system. }\end{array}$ \\
\hline \multicolumn{2}{|c|}{$\begin{array}{l}\text { 1.2 Existence: There is no tagged business } \\
\text { fact in the XBRL instance document that is not } \\
\text { present in the traditional format document. }\end{array}$} & $\begin{array}{l}\text { 2. Tagging is Accurately and } \\
\text { Consistently Applied: With respect to } \\
\text { both standard tags and extensions, the tags } \\
\text { and related contextual structuring } \\
\text { attributes (for example, context, units, } \\
\text { footnotes) accurately reflect the } \\
\text { corresponding data in the source document } \\
\ldots .\end{array}$ & $\begin{array}{l}\text { M: Trace from the XBRL instance document to the original document to } \\
\text { check if the tagged facts are present in the original document. } \\
\text { IS: Intelligent software can be programmed to tag all the business facts. } \\
\text { Compare programmatically each tagged fact prepared for the SEC filing } \\
\text { with the tagged facts by the intelligent system. }\end{array}$ \\
\hline \multirow{2}{*}{$\begin{array}{l}\text { 1.3 Accuracy: The values } \\
\text { of all business concepts } \\
\text { tagged in the XBRL } \\
\text { instance document and / or } \\
\text { the corresponding attribute } \\
\text { values (such as context, } \\
\text { unit, etc.) accurately } \\
\text { represent the facts in the } \\
\text { traditional format } \\
\text { document. }\end{array}$} & $\begin{array}{r}\text { 1.3.1 Element } \\
\text { Accuracy }\end{array}$ & $\begin{array}{l}\text { 2. Tagging is Accurately and } \\
\text { Consistently Applied: With respect to } \\
\text { both standard tags and extensions, the tags } \\
\text { and related contextual structuring } \\
\text { attributes (for example, context, units, } \\
\text { footnotes) accurately reflect the } \\
\text { corresponding data in the source document }\end{array}$ & $\begin{array}{l}\text { M: Trace from the text document to the instance document to check if the } \\
\text { values of all the business facts are the same as the values on the rendered } \\
\text { document. } \\
\text { IS: Intelligent software can be programmed to read the values of the } \\
\text { business facts from the original document and compare them with the } \\
\text { corresponding values in the instance document. }\end{array}$ \\
\hline & $\begin{array}{r}\text { 1.3.2 Attribute } \\
\text { Accuracy }\end{array}$ & $\begin{array}{l}\text { 2. Tagging is Accurately and } \\
\text { Consistently Applied: With respect to } \\
\text { both standard tags and extensions, the tags } \\
\text { and related contextual structuring } \\
\text { attributes (for example, context, units, } \\
\text { footnotes) accurately reflect the } \\
\text { corresponding data in the source document } \\
\ldots\end{array}$ & $\begin{array}{l}\text { M: Trace from the text document to the instance document to check if the } \\
\text { values of all the attributes are the same as the values of these attributes in } \\
\text { the instance document. } \\
\text { IS: Intelligent software can be programmed to read the values of the } \\
\text { business items from the original document and compare them with the } \\
\text { corresponding values in the instance document. }\end{array}$ \\
\hline
\end{tabular}


Table 2: Proposed Assertions about Meta-Data in XBRL Instance Document along with AICPA SOP 09-1 Assertions (AICPA 2009, Appendix C) and Suggested Assurance Procedures.

\begin{tabular}{|c|c|c|}
\hline Proposed Specific Assertions & $\begin{array}{c}\text { (Approximately or partially) } \\
\text { Equivalent SOP 09-1 } \\
\text { Assertions }\end{array}$ & Procedures as items of evidence pertaining to the assertion \\
\hline $\begin{array}{l}\text { 2.1 Well-Formedness: The XBRL } \\
\text { instance document is well-formed, } \\
\text { i.e., it complies with all XML syntax } \\
\text { rules. }\end{array}$ & No Equivalent Assertion & $\begin{array}{l}\text { Manual (M): Evaluate the error messages generated by the software to verify } \\
\text { well-formedness. } \\
\text { Intelligent Software (IS): Utilize any approved XML parsing software to } \\
\text { verify that the instance document is well-formed. }\end{array}$ \\
\hline $\begin{array}{l}\text { 2.2 Validity: The XBRL instance } \\
\text { document is valid, i.e., it complies } \\
\text { with all rules of XBRL and } \\
\text { referenced XBRL taxonomies. }\end{array}$ & $\begin{array}{l}\text { 2. Tagging is Accurately and } \\
\text { Consistently Applied: With respect to } \\
\text { both standard tags and extensions, the } \\
\text { tags and related contextual structuring } \\
\text { attributes (for example, context, units, } \\
\text { footnotes) accurately reflect the } \\
\text { corresponding data in the source } \\
\text { document .... Other metadata has been } \\
\text { provided in a manner consistent with } \\
\text { applicable requirements (for example, } \\
\text { SEC rules). }\end{array}$ & $\begin{array}{l}\text { M: Evaluate the error messages generated by the software to verify validity. } \\
\text { IS: Utilize any approved XML validating parsing software to verify that the } \\
\text { instance document is valid. }\end{array}$ \\
\hline $\begin{array}{l}\text { 2.3 Proper Representation: The } \\
\text { tagged business fact in the XBRL } \\
\text { instance document properly } \\
\text { represents the facts in the traditional } \\
\text { format document }\end{array}$ & $\begin{array}{l}\text { 2. Tagging is Accurately and } \\
\text { Consistently Applied: With respect to } \\
\text { both standard tags and extensions, the } \\
\text { tags and related contextual structuring } \\
\text { attributes (for example, context, units, } \\
\text { footnotes) accurately reflect the } \\
\text { corresponding data in the source } \\
\text { document .... Other metadata has been } \\
\text { provided in a manner consistent with } \\
\text { applicable requirements (for example, } \\
\text { SEC rules). }\end{array}$ & $\begin{array}{l}\text { M: Trace from the instance document to the text document to check if the } \\
\text { tags, as they are defined in the XBRL taxonomies, properly represent the } \\
\text { facts of the traditional format document. } \\
\text { IS: Intelligent software can be programmed to maintain a mapping between } \\
\text { the facts of the traditional format document and the elements of the instance } \\
\text { document to aid in manual decision making. }\end{array}$ \\
\hline
\end{tabular}




\section{Table 3: Proposed Assertions about Meta-Data External to XBRL Instance Document along with AICPA SOP 09-1 Assertions}

(AICPA 2009, Appendix C) and Suggested Assurance Procedures.

\begin{tabular}{|c|c|c|}
\hline Proposed Specific Assertions & $\begin{array}{c}\text { (Approximately or partially) Equivalent } \\
\text { SOP 09-1 Assertions }\end{array}$ & $\begin{array}{l}\text { Procedures as items of evidence pertaining } \\
\text { to the assertion }\end{array}$ \\
\hline $\begin{array}{l}\text { 3.1 Proper Taxonomies: The business facts } \\
\text { are tagged in the XBRL instance document } \\
\text { using appropriate general and industry- } \\
\text { specific XBRL taxonomies. }\end{array}$ & $\begin{array}{l}\text { 1. Identification and Version of Taxonomies: The taxonomies } \\
\text { selected are appropriate for the entity's intended purpose and } \\
\text { have been used in creating the XBRL-tagged data. }\end{array}$ & $\begin{array}{l}\text { Manual (M): Compare the discoverable taxonomy set } \\
\text { in the instance document with the available approved } \\
\text { and acknowledged XBRL taxonomies to check if all } \\
\text { the appropriate taxonomies are used and all the used } \\
\text { taxonomies are appropriate. } \\
\text { Intelligent Software (IS): Utilize XBRL processing } \\
\text { software to identify and visualize the discoverable } \\
\text { taxonomy set in the instance document. }\end{array}$ \\
\hline $\begin{array}{l}\text { 3.2 Valid Taxonomy Extensions: The } \\
\text { XBRL taxonomy extensions referenced by } \\
\text { the XBRL instance document are valid, i.e., } \\
\text { they comply with all rules of XML and } \\
\text { XBRL. }\end{array}$ & $\begin{array}{l}\text { 2. Tagging is Accurately and Consistently Applied: With } \\
\text { respect to both standard tags and extensions, the tags and related } \\
\text { contextual structuring attributes (for example, context, units, } \\
\text { footnotes) accurately reflect the corresponding data in the } \\
\text { source document .... Other metadata has been provided in a } \\
\text { manner consistent with applicable requirements (for example, } \\
\text { SEC rules). }\end{array}$ & $\begin{array}{l}\text { M: Evaluate the error messages generated by the } \\
\text { software to verify validity. } \\
\text { IS: Utilize approved XBRL processing software to } \\
\text { verify that the taxonomy extensions are valid. }\end{array}$ \\
\hline $\begin{array}{l}\text { 3.3 Proper Extension Elements: The new } \\
\text { elements in the XBRL taxonomy extensions } \\
\text { referenced by the XBRL instance document } \\
\text { are introduced appropriately, i.e., the } \\
\text { extension tag along with its appropriate } \\
\text { attributes is created only when there is no } \\
\text { standard tag available. }\end{array}$ & $\begin{array}{l}\text { 3. Creation of Extensions: Extensions have been created only } \\
\text { when no element exists in the specified base taxonomy(ies) or } \\
\text { modules that is the same as or accurately reflects a specified } \\
\text { element in the source document..... }\end{array}$ & $\begin{array}{l}\text { M: Analyze new elements in XBRL taxonomy } \\
\text { extensions to verify that they are defined properly and } \\
\text { they not duplicate unnecessarily existing elements. } \\
\text { IS: Utilize XBRL processing software to examine new } \\
\text { elements in XBRL taxonomy extensions. }\end{array}$ \\
\hline $\begin{array}{l}\text { 3.4 Proper Linkbases: The linkbases in the } \\
\text { XBRL taxonomy extensions referenced by } \\
\text { the XBRL instance document are } \\
\text { appropriate. }\end{array}$ & $\begin{array}{l}\text { 6. Label and Label Linkbase: Labels in the Label Linkbase are } \\
\text { the same as or accurately reflect respective captions in the ... } \\
\text { source ... and with the definition of the element. } \\
\text { 7. Calculations and Calculation Linkbase: Calculations in the } \\
\text { XBRL instance document and in the calculation linkbase are } \\
\text { complete and accurate and include only values that appear in .. } \\
\text { 8. Presentation and Presentation Linkbase: Presentation of } \\
\text { line items as indicated in the presentation linkbase is consistent } \\
\text { with the respective presentation of those items in the source ... }\end{array}$ & $\begin{array}{l}\text { M: Analyze new and changed arcs in the linkbases of } \\
\text { XBRL taxonomy extensions to verify that they are } \\
\text { defined properly. } \\
\text { IS: Utilize XBRL processing software to examine new } \\
\text { and changed arcs in the linkbases of XBRL taxonomy } \\
\text { extensions. }\end{array}$ \\
\hline
\end{tabular}


Figure 1: A Conceptual Framework of Assertions for XBRL Instance Document

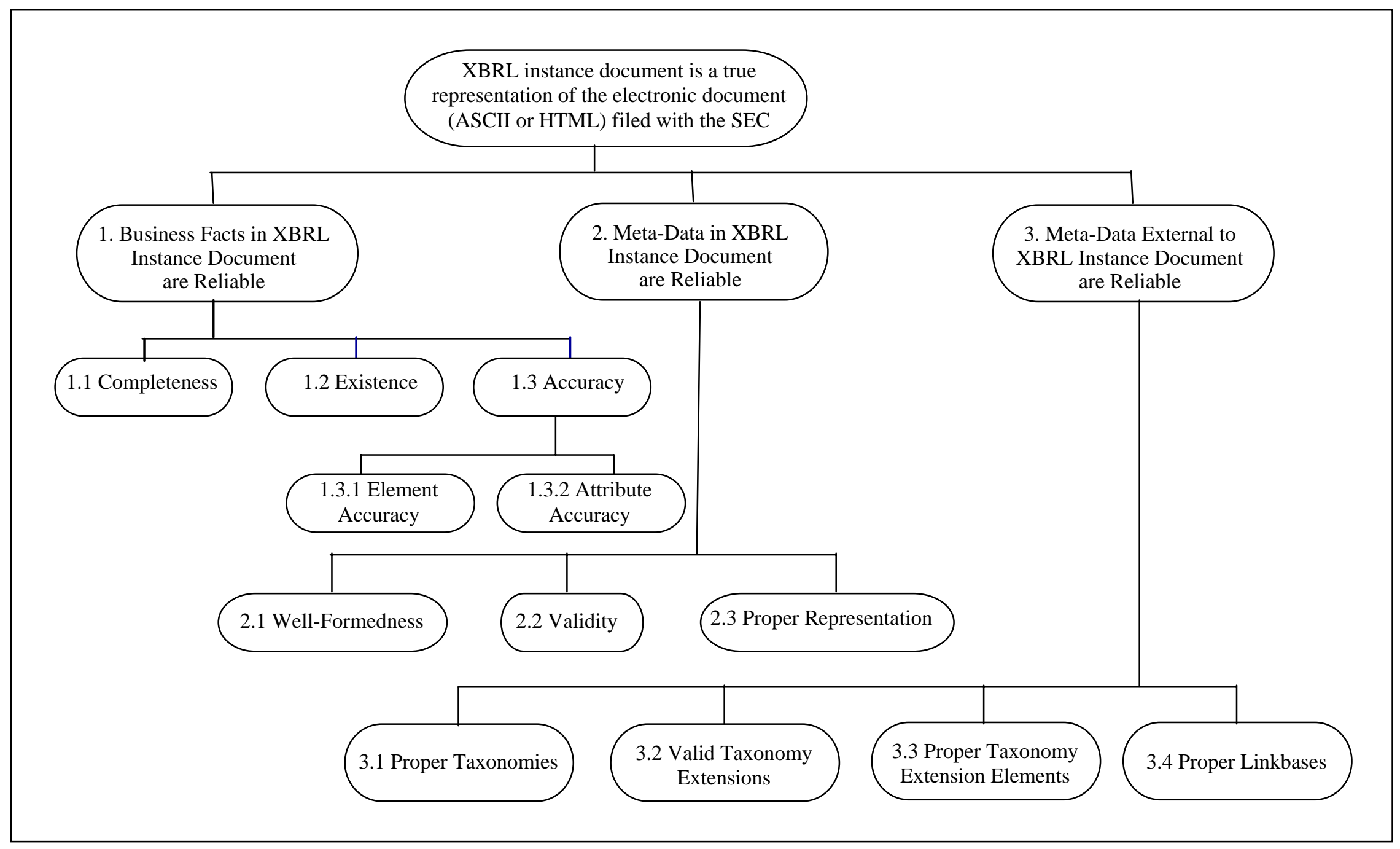

